\title{
Evidence for size and sex-specific dispersal in a cooperatively breeding cichlid fish
}

\author{
K. A. STIVER, ${ }^{*}$ J. K. DESJARDINS, ${ }^{*}$ J. L. FITZPATRICK,+B. NEFF, J. S. QUINN† and S. BALSHINE* \\ *Department of Psychology, +Department of Biology, McMaster University, Hamilton, Ontario, Canada, L8S 4K1, $\ddagger$ Department of \\ Biology, University of Western Ontario, London, Ontario, Canada, N6A 5B7
}

\begin{abstract}
African Great Lake cichlid populations are divided into thousands of genetic subpopulations. The low gene flow between these subpopulations is thought to result from high degrees of natal philopatry, heavy predation pressure, and a patchy distribution of preferred habitats. While predation pressure and habitat distribution are fairly straightforward to assess, data on dispersal distances and rates are scarce. In fishes, direct observations of dispersal events are unlikely, but dispersal can be studied using molecular markers. Using seven microsatellite loci, we examined dispersal in the cooperatively breeding cichlid fish, Neolamprologus pulcher. As this species is found in well-defined groups clustered into subpopulations, we could assess dispersal on a narrow (within subpopulation) and broad (between subpopulation) scale. While fish were generally more related to others in their own subpopulation than they were to fish from other subpopulations, large males diverged from this pattern. Large males were more related to other large males from different subpopulations than they were to large males from their own subpopulation, suggesting more frequent dispersal by large males. Across subpopulations, relatedness between large males was higher than the relatedness among large females; this pattern was not detected in small males and small females. Within a subpopulation, individuals appeared to be preferentially moving away from relatives, and movement was unrestricted by the physical distance between groups. Our results highlight the importance of examining multiple spatial scales when studying individual dispersal biases.
\end{abstract}

Keywords: genetic similarity, Lake Tanganyika, microsatellites, Neolamprologus pulcher, relatedness values, sex-biased dispersal

Received 19 November 2006; revision received 26 February 2007; accepted 20 March 2007

\section{Introduction}

Dispersal is associated with increased physiological stress and mortality (Koenig \& Pitelka 1981). However, individuals may gain fitness benefits when dispersing from their natal territory, including inbreeding avoidance, increased access to resources (e.g. mates, food, shelter), and decreased competition with relatives (Hamilton 1967; Bengtsson 1978; Pusey 1987; Perrin \& Mazalov 2000). Two common questions about dispersal are: which sex most often disperses, and when in the lifespan is this sex bias evident? These questions are of particular interest in highly social species, such as cooperatively breeding vertebrates, where subordinate

Correspondence: K. A. Stiver, Fax: 905-529-6225; E-mail: stiverka@mcmaster.ca group members aid in rearing offspring of dominants and generally exhibit delayed dispersal (see Hatchwell \& Komdeur 2000; Ekman et al. 2001). Here, we examine dispersal biases in the cooperatively breeding cichlid fish, Neolamprologus pulcher.

As costs and benefits of dispersal may differ between males and females, one sex often disperses more frequently or farther than the other. For example, female-biased dispersal is common in birds, while male-biased dispersal is the norm in mammals (Greenwood 1980; Pusey 1987). Although inbreeding avoidance can favour sex-biased dispersal (Bengtsson 1978; Parker 1979, 1983; Waser et al. 1986; Pusey 1987; Motro 1991), which sex disperses is strongly influenced by sex differences in the costs and benefits of philopatry (e.g. the importance of having knowledge of terrain, shelter and food, and the intensity of competition, 
see Greenwood 1980; Perrin \& Mazalov 2000; Leturque \& Rousset 2004). Individuals may compete over access to mates (local mate competition or LMC; Hamilton 1967) and/or other resources such as food and shelter (local resource competition or LRC; Clarke 1978). A sex difference in intensity of local competition (and therefore in the potential costs of kin competition) often leads to the evolution of sex-biased dispersal and/or a bias in the birth sex-ratio (see Leturque \& Rousset 2004). In polygynous species, it is generally assumed that LMC is more costly to males, while LRC is more costly to females (Hamilton 1967; Clarke 1978; Perrin \& Mazalov 2000; Leturque \& Rousset 2004). Perrin \& Mazalov's (2000) theoretical model of the effects of intrasexual competition on dispersal predicts that male-biased dispersal evolves in polygynous species where LMC between males exceeds LRC between females. Their model also supported the general expectation that birth sex-ratio will be biased in favour of the dispersing sex (Perrin \& Mazalov 2000). Leturque \& Rousset (2004) demonstrated that even in species with a fixed and unbiased birth sex-ratio, and with consideration of intersexual competition, male-biased dispersal occurs as a result of increased local competition of males relative to females.

When examining sex-biased dispersal, it is important to ensure that the individuals being compared belong to the same cohort (Goudet et al. 2002), as older individuals have suffered increased mortality, have had more time to move, and are the potential parents of younger individuals. Additionally, the life stage at which dispersal occurs can have large fitness consequences, and many species display a size/age bias at which individuals typically disperse. While most vertebrates disperse as juveniles (Greenwood \& Harvey 1982; Cockburn 1992; Johst \& Brandl 1999), particular ecological conditions, such as high constraints on independent survival or breeding (Pruett-Jones \& Lewis 1990; Emlen 1994), can favour delayed dispersal. Dispersing at adult size, and when sexually mature, may better prepare individuals for avoiding dispersal costs (such as predation, Paine 1976; Nilsson \& Brönmark 2000), and to compete for mates or territories (Emlen 1982; Ekman et al. 2004).

While dispersal of individuals between social groups of cooperative breeders has been previously examined, in the majority of species studied, the large home range of one group and expansive space between groups and subpopulations precludes a clear study of dispersal between subpopulations (see Komdeur 1992; Russell \& Rowley 1993; Cooper \& Walters 2002). However, our study species, N. pulcher, is ideal for examination of dispersal, as groups of $N$. pulcher occupy a relatively small area (median size $3150 \mathrm{~cm}^{2}$, Balshine et al. 2001) and are closely clustered in space into subpopulations. The small geographical scale at which these fish live provides a useful opportunity to study dispersal patterns at different scales (both within and between subpopulations) in a cooperative breeder.
Although the possibility of sex-biased dispersal in N.pulcher has been previously discounted (Dierkes et al. 2005), malebiased dispersal was suggested by the findings of Stiver et al. (2004), and the life-history traits of N. pulcher support such a prediction (Greenwood 1980; Perrin \& Mazalov 2000). First, reproductive success is tied directly to territory acquisition and social dominance in N. pulcher (Taborsky \& Limberger 1981; Balshine-Earn et al. 1998; Stiver et al. 2006); hence, LMC will exceed LRC in both sexes. Second, male $N$. pulcher can simultaneously hold up to six different territories, while females are capable of holding only one (Limberger 1983; Desjardins et al. submitted). Therefore, male reproductive success is necessarily more variable, leading to higher mating competition among males than females. Additionally, experiments revealed that if there is a female breeding vacancy, the male associated with that territory significantly decreases time spent on the territory; in contrast, a male breeding vacancy did not influence the amount of time the female breeder spends on her territory. These results suggest that males are motivated to remain on the territory by the presence of a reproductively active female breeder, while females' motivation is not as strongly influenced by the presence of a male breeder (Stiver et al. 2006). We also predict that large fish disperse to a greater extent than small fish, as large fish can better resist predation risks associated with moving (Paine 1976; Nilsson \& Brönmark 2000) and are more likely than small individuals to gain immediate fitness benefits by becoming breeders following dispersal (Emlen 1982; Ekman et al. 2004). Taken together, these findings suggest that dispersal will be most apparent in large male individuals. We used pairwise relatedness estimates to test these predictions by examining at a broad scale (between subpopulations) as well as dispersal at a more local scale (between the groups within subpopulations).

\section{Materials and methods}

\section{Neolamprologus pulcher natural history}

Neolamprologus pulcher are small fish endemic to Lake Tanganyika and are found at depths of 3-45 m (Taborsky 1984) throughout the southern basin from Kalila, Tanzania in the east to Cape Tembwe, Congo in the west (Konings 1998). Individuals live in social groups composed of one dominant breeding pair, and one to 15 subordinates of both sexes called 'helpers' (average five helpers; Balshine et al. 2001; Stiver et al. 2006). The mean relatedness between group members is 0.16 , and helpers are more related to the breeding female than they are to the breeding male (Stiver et al. 2005). Differences in relatedness appear to result both from increased turnover rates of males relative to females (Stiver et al. 2004) and the fact the females are more likely than males to inherit the territory they are helping in 


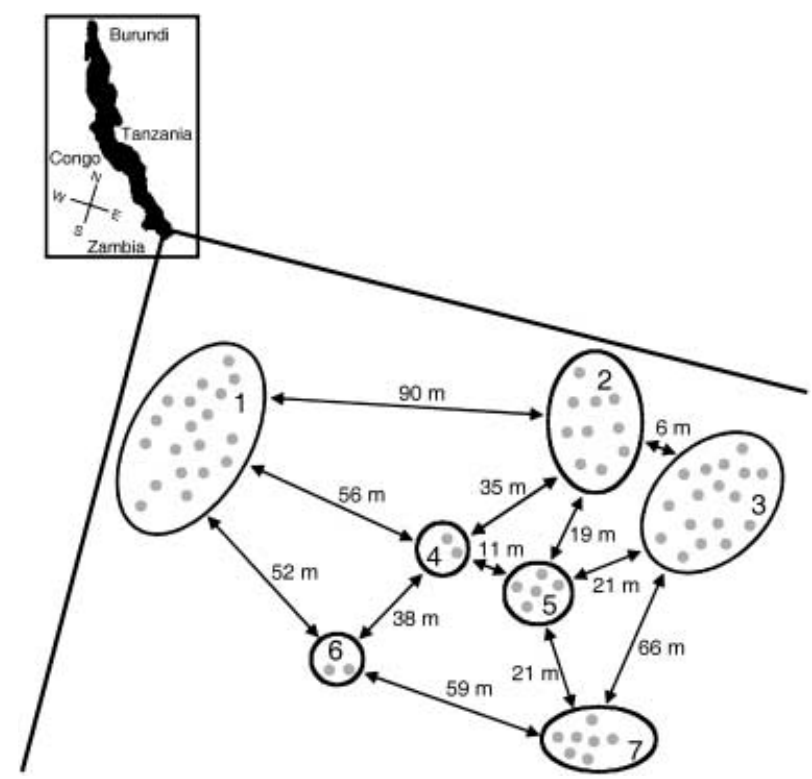

Fig. 1 Our study site was located in the southern basin of Lake Tanganyika. This is a graphic representation of the location of subpopulations relative to one another, and the distances between them (distances and sizes not to scale; see Table 1 for sample sizes per subpopulation). Relative positions of the groups included in the group-group comparisons are indicated by the grey circles.

(possibly their natal territory; Dierkes et al. 2005; Stiver et al. 2006). Although they do not appear to be biased, birth sex-ratio and sex-bias in mortality of wild N. pulcher are not currently known, as individuals cannot be reliably sexed until they are above $3 \mathrm{~cm}$ in size.
Each social group defends a territory composed of rocks used as shelters, and as a brood chamber, where external fertilization and early development of young occurs (Balshine et al. 2001). Young begin to 'help' at around 40 days of age, continuing until death or until they become a dominant breeder (for further descriptions of helping behaviours and life history trajectories, see Taborsky \& Limberger 1981; Balshine-Earn et al. 1998; Stiver et al. 2004, 2005). Female N. pulcher (both helpers and breeders), perform more care and help than males (Balshine et al. 2001; Stiver et al. 2005).

For this study, we sampled 445 individuals from 91 social groups in seven different subpopulations (see Fig. 1 and Table 1 for an overview of the subpopulations and groups included in this study). Social groups naturally cluster into 'subpopulations', each containing between two to over 200 groups, that are separated from one another by areas of substrate uninhabited by N. pulcher. The mean distance between adjacent subpopulations was $22.3 \mathrm{~m}$ (see Table 2 for further information on the distances between subpopulations used in this study). Although predation limits the movement of individual fish (Balshine et al. 2001; Heg et al. 2004), and genetic similarity between individuals in the subpopulations decreases as the physical distance between them increases (Stiver et al. 2004), subordinate helpers do briefly visit neighbouring groups within their own subpopulation (Bergmüller et al. 2005). Additionally, helpers may disperse and join new groups and often increase their relative rank, sometimes gaining a breeding position as a result of this movement (Stiver et al. 2004).

Table 1 Numerical breakdown of individuals included in the subpopulation and group relatedness comparisons, tallied by subpopulation affiliation. Individuals of unknown sex (fish cannot be sexed accurately until over $3 \mathrm{~cm} \mathrm{SL}$ ) are included in the count of total individuals. Groups were included in the group-group comparisons only when $50 \%$ or more of the group members were successfully genotyped. See also Fig. 1 for a schematic of the subpopulations and of the groups involved in the group-group comparisons

\begin{tabular}{|c|c|c|c|c|c|c|c|c|}
\hline & \multicolumn{8}{|c|}{ Subpopulation } \\
\hline & Total & 1 & 2 & 3 & 4 & 5 & 6 & 7 \\
\hline \multicolumn{9}{|c|}{ Individuals sampled for subpopulation-subpopulation comparisons } \\
\hline Total groups sampled & 91 & 35 & 14 & 25 & 2 & 4 & 3 & 8 \\
\hline Total individuals & 445 & 143 & 85 & 110 & 16 & 22 & 22 & 47 \\
\hline Breeder-size males & 105 & 31 & 22 & 29 & 6 & 8 & - & 9 \\
\hline Breeder-size females & 95 & 33 & 17 & 27 & - & 5 & 5 & 8 \\
\hline Helper-size males & 83 & 28 & 21 & 16 & - & 5 & - & 13 \\
\hline Helper-size females & 112 & 43 & 22 & 21 & - & - & 9 & 17 \\
\hline \multicolumn{9}{|c|}{ Individuals sampled for group-group comparisons } \\
\hline Total groups sampled & 60 & 19 & 10 & 17 & 2 & 5 & 2 & 7 \\
\hline Total individuals & 374 & 99 & 73 & 94 & 16 & 20 & 20 & 52 \\
\hline Breeder-size males & 83 & 17 & 17 & 23 & 6 & 7 & 4 & 9 \\
\hline Breeder-size females & 73 & 22 & 14 & 19 & 2 & 5 & 3 & 8 \\
\hline Helper-size males & 89 & 23 & 21 & 16 & 4 & 5 & 3 & 18 \\
\hline Helper-size females & 106 & 35 & 19 & 19 & 4 & 3 & 9 & 17 \\
\hline
\end{tabular}


Table 2 The mean (and range) distances measured between subpopulations and between groups within subpopulations. The distances presented include those between adjacent groups (nearest neighbours) and those between all possible group and subpopulation comparison pairs within our study area. The distance between groups was measured from the centre of each territory; most neighbouring territories were contiguous. In contrast, the distance between subpopulations was measured from the nearest edge of one subpopulation to the nearest edge of the next one

\begin{tabular}{ll}
\hline Comparisons & $\begin{array}{l}\text { Distance } \\
\text { in metres }\end{array}$ \\
\hline Subpopulation pairs & Mean (range) \\
$\quad$ Distance between adjacent subpopulations & $22.3(5.6-52.0)$ \\
$\quad$ Distance between all subpopulation pairs & $57.9(5.6-193.6)$ \\
Group pairs (within a subpopulation) & $1.6(0.4-4.5)$ \\
$\quad$ Distance between adjacent groups & $14.2(0.4-49.4)$ \\
\hline Distance between all possible pairs of groups & \\
\hline
\end{tabular}

\section{Sample collection}

Fieldwork was conducted between March and April of 2004 on the Zambian shores of Lake Tanganyika (Kasakalawe Bay, $8^{\circ} 46.87^{\prime} \mathrm{S}, 31^{\circ} 04.88^{\prime} \mathrm{E}$ ). Subpopulations, and clustered social groups within these subpopulations, were located and monitored at depths of $8.5-11.5 \mathrm{~m}$ using SCUBA. Behavioural observations (including the determination of each fish's individual status) were recorded on PVC slates. The distances between groups (in $\mathrm{cm}$ ) and between subpopulations (in $\mathrm{m}$ ) were measured using underwater measuring tapes (for further details of the study area and general field methods, see Balshine-Earn et al. 1998; Balshine et al. 2001; Werner et al. 2003; Stiver et al. 2004, 2005, 2006; Fitzpatrick et al. 2006).

Of the total 445 individuals genotyped in this study, 45 were captured individually using hand nets and transparent PVC tubes, while the remaining 400 were captured along with their entire group using a tent net (see Morley \& Balshine 2003) and 3-7 mL of quinaldine (2-methylquinoline; $\mathrm{C}_{6} \mathrm{H}_{4} \mathrm{~N}: \mathrm{C}\left(\mathrm{CH}_{3}\right) \mathrm{CH}: \mathrm{CH}$, a common fish anaesthetic).
Individually captured fish were measured and sexed by examination of the genital papilla (Balshine-Earn et al. 1998) and a small tissue sample was cut from either the dorsal or anal fin. Fish captured with their group were brought to the surface and had their body length (SL; to the nearest $0.01 \mathrm{~cm}$ ) and mass (to the nearest $0.001 \mathrm{~g}$ ) recorded prior to sacrifice by an overdose of ethyl 4-aminobenzoate (Sigma-Aldrich) and cervical severance. Sex was determined by examination of gonads and a sample of muscle tissue was taken. Tissue samples were preserved in 95\% ethanol for storage and transport.

\section{Genetic methods}

DNA was extracted using QIAGEN DNeasy tissue kits and amplified using seven microsatellite loci (see Table 3) and the M13 labelling method (see Schuelke 2000 for full overview). Primer sets were used in combination in a polymerase chain reaction [PCR (multiplexing: Neff et al. 2000)]. Samples were amplified using Biometra T1 and TGradiant thermocyclers set at the following parameters (as in Schuelke 2000): $94{ }^{\circ} \mathrm{C}$ (5 min); eight cycles of $94^{\circ} \mathrm{C}$ (45 s), $60-54{ }^{\circ} \mathrm{C}\left(45 \mathrm{~s},-1{ }^{\circ} \mathrm{C} /\right.$ cycle), $72{ }^{\circ} \mathrm{C}(30 \mathrm{~s}) ; 34$ cycles of $94{ }^{\circ} \mathrm{C}(45 \mathrm{~s}), 54{ }^{\circ} \mathrm{C}(45 \mathrm{~s}), 72^{\circ} \mathrm{C}(30 \mathrm{~s}) ;$ nine cycles of $94{ }^{\circ} \mathrm{C}$ $(45 \mathrm{~s}), 53^{\circ} \mathrm{C}(45 \mathrm{~s}), 72{ }^{\circ} \mathrm{C}(30 \mathrm{~s}) ; 72{ }^{\circ} \mathrm{C}(10 \mathrm{~min})$. PCR product was visualized and scored using a Beckmann-Coulter CEQ 8000 genetic analysis system (software version 8.0.52, instrument version 6.0.2, fragment analysis algorithm version 2.2.1). Peaks were evaluated and scored visually by an observer blind to sample identity. If amplification and visualization failed, another attempt was made for each locus. Individuals were included in the analyses only if they were genotyped at three or more loci (mean number of loci typed per individual $=6.7$; range $3-7$ ).

\section{Relatedness calculations}

Allele frequencies were estimated using CERVUS 2.0 and based on all genotyped individuals in the population. The same allele frequency estimates were used for all relatedness

Table 3 The seven microsatellite loci used in this study with their expected $\left(H_{\mathrm{E}}\right)$ and observed $\left(H_{\mathrm{O}}\right)$ heterozygosities and polymorphic information contents (PIC; based on population-based calculations using CERVUs version 2.0, Marshall et al. 1998)

\begin{tabular}{|c|c|c|c|c|c|}
\hline Locus & Reference & No. of alleles & $H_{\mathrm{O}}^{*}$ & $H_{\mathrm{E}}$ & PIC \\
\hline LOC101 & Brandtmann et al. (1999) & 34 & 0.342 & 0.851 & 0.839 \\
\hline ML007 & Kohler (1997) & 13 & 0.402 & 0.434 & 0.415 \\
\hline Ppun21 & Taylor et al. 2002 & 19 & 0.798 & 0.863 & 0.849 \\
\hline Pzeb1 & Parker \& Kornfield (1996) & 9 & 0.483 & 0.589 & 0.532 \\
\hline Pzeb3 & Parker \& Kornfield (1996) & 33 & 0.620 & 0.878 & 0.869 \\
\hline TmoM13 & Zardoya et al. (1996) & 31 & 0.683 & 0.933 & 0.928 \\
\hline US783 & Schliewen et al. (2001) & 37 & 0.542 & 0.928 & 0.923 \\
\hline
\end{tabular}

*Loci are generally in Hardy-Weinberg equilibrium within each subpopulation.

(C) 2007 The Authors

Journal compilation @ 2007 Blackwell Publishing Ltd 
calculations. Mean relatedness was estimated between individuals using KINSHIP 1.3.1 (Goodnight \& Queller 1999; following, among others, Burland et al. 2001; SchulteHostedde et al. 2001; Richardson et al. 2002; Whittingham et al. 2006). Other relatedness estimators (e.g. Wang 2002) were examined and yielded similar results. Some relatedness estimators, including Queller's $r$, occasionally yield negative values; these values reflect a pair of individuals whose genetic similarity is less than that of two individuals chosen randomly from the population (Queller \& Goodnight 1989; Rousset 2002).

To examine size- and sex-biased patterns of relatedness, we calculated relatedness of individuals within a demographic category (individuals assigned to the same size and sex class). Large individuals have suffered increased mortality relative to small individuals and are also the potential parents of these small fish (Goudet et al. 2002). Therefore, to minimize the likelihood of comparing across cohorts, and to determine the typical size of dispersing individuals, we divided all individuals into two size classes. We classified 'large' individuals as those that fell within the $90 \%$ confidence interval of a breeder's body length based on breeder sizes as measured in our field study population $(\geq 4.5 \mathrm{~cm}$ ). All other individuals were classed as 'small'. This nonsex-specific confidence interval for 'large size' was chosen to equalize the potential effects of body size on dispersal costs between males and females.

\section{Competition for breeding positions}

We examined relative mating competition in males vs. females by examining 82 social groups for which we had complete size and sex data of all group members. In these groups, we counted the number of established breeders, the number of groups that each breeder was dominant in, and the number of males and females present that could potentially compete for these 82 territories if a vacancy arose (competitors were defined as large/breeder-sized individuals). As females do not hold multiple territories, established female breeders were excluded from the count of competitors for potential female breeding positions.

\section{Within-subpopulation analyses}

As previous work has shown that there is isolation by distance between $N$. pulcher subpopulations (Stiver et al. 2004), we tested whether distance similarly restricted movement within subpopulations by comparing the mean relatedness of each size and sex class between groups to the physical distance separating them (measured from territory centre to territory centre). However, the maximum distance that can be travelled from a specific group within a subpopulation depends both on overall subpopulation area and the position of the group within the subpopulation.
To control for these issues, we ranked the mean pairwise relatedness and distance of each group to each other group in the subpopulation. These ranks were averaged for each group-group comparison and used as the variables for the correlation test (see Knight et al. 1999; Prugnolle \& de Meeus 2002; for a similar analysis). Using this same ranking methodology, we also compared the mean relatedness between males and females within a size class to the distance between their groups to determine the relative movements of males vs. females.

To determine whether there was evidence of size- or sexbiased dispersal within a subpopulation, we compared the mean relatedness between males from different groups to the mean relatedness between females from different groups. Comparisons were made within the large and small size classes. Groups were included in our analyses only when $50 \%$ or more of the group had been genotyped at three or more loci (resulting in a sample of 60 groups in seven subpopulations), and comparisons were made only between groups that belonged to the same subpopulation.

\section{Between-subpopulation analyses}

We also examined whether there was evidence for size- or sex-biased dispersal of individuals between subpopulations. Relatedness was estimated between individuals of the same size and sex class that belonged to different subpopulations. We then compared mean values for males vs. females in the same size class to test for dispersal biases. Seven subpopulations were included in these analyses (see Table 1).

\section{Statistical analyses}

Due to the nature of pairwise comparisons, individuals contribute to multiple data points within a sample, and our data were nonindependent. Thus, we controlled for pseudoreplication in several ways. Within-subpopulation analyses included physical distance measures, and using comparisons between individuals necessitated reusing the same distance measure multiple times. Therefore, to decrease the number of pairwise comparisons, we calculated a mean relatedness value for each size/sex class for each group-to-group comparison. When the number of paired comparisons exceeded 1000, we randomly selected 1000 pairwise relatedness estimates for each size/sex class (the initial number of paired comparisons ranged from 1057 to 4550). Further, to completely eliminate the issue of nonindependence, we analysed both a broad and restricted sample for each test. The broad sample included all of the comparison pairs as described above, while the restricted samples used pairs of individuals or groups that were randomly selected such that no individual/group contributed to more than one paired comparison. Results for these restricted sample analyses mirror the findings of the broad 
Table 4 Mean relatedness of individuals to others (in the same size and sex class) from their own group, from different groups in the same subpopulation, and from different subpopulations. $N$ is the number of paired comparisons (different subpopulation comparisons include 1000 randomly sampled pairs out of the all possible paired comparisons)

\begin{tabular}{|c|c|c|c|c|c|c|}
\hline & \multicolumn{6}{|c|}{ Compared to individuals from: } \\
\hline & \multicolumn{2}{|l|}{ Own group } & \multicolumn{2}{|c|}{$\begin{array}{l}\text { Different groups in same } \\
\text { subpopulation }\end{array}$} & \multicolumn{2}{|c|}{ Different subpopulations } \\
\hline & Mean \pm SE & $N$ & Mean \pm SE & $N$ & Mean \pm SE & $N$ \\
\hline Large males & $0.164 \pm 0.044$ & 51 & $0.017 \pm 0.009$ & 300 & $0.036 \pm 0.007$ & 1000 \\
\hline Large females & $0.142 \pm 0.059$ & 23 & $-0.002 \pm 0.009$ & 332 & $-0.007 \pm 0.005$ & 1000 \\
\hline Small males & $0.170 \pm 0.027$ & 82 & $0.018 \pm 0.009$ & 148 & $0.003 \pm 0.006$ & 1000 \\
\hline Small females & $0.185 \pm 0.025$ & 129 & $0.033 \pm 0.010$ & 203 & $-0.005 \pm 0.005$ & 1000 \\
\hline
\end{tabular}

sample analyses and are summarized in the Appendix. Finally, all tests were based on resampling and randomization tests performed using RUNDOM Projects 2.0 Lite ( Jadwiszczack 2002; all tests used $N=10000$ randomizations). Unless otherwise stated, sample sizes refer to the number of paired comparisons. All $P$ values reported are two-tailed.

\section{Results}

\section{Competition for breeding positions}

In the 82 groups, there were 82 established female breeders (each dominant in only one group), and 69 established male breeders (each dominant in 1-4 groups). There were more potential male competitors ( $N=134$ large males) in these 82 groups than there were breeding positions they could potentially fill. Conversely, the number of breeding positions for females $(N=82)$ exceeded the number of large females capable of filling them ( $N=47$ large females), suggesting that that there is increased mating competition for males relative to females. This difference in number of competitors held when a sex-specific criterion for 'breedersized' was used (98 large males and 69 large females; see Stiver et al. 2006).

\section{Dispersal within a subpopulation}

Individuals were more related to fish (within the same size and sex class) in their own groups than they were to fish (within the same size and sex class) in different groups from the same subpopulation (two-sample randomization/ permutation test; males: all $P$ values $<0.0001$; Table 4 ) or to fish from different subpopulations (all $P$ values $<0.0001$; Table 4).

We found no evidence that fish dispersed preferentially to nearby groups; in contrast, mean pairwise relatedness between groups increased as the physical distance between them increased (Table 5). This positive correlation
Table 5 Subpopulation level correlation analyses comparing the mean relatedness between specific types of individuals to the distance between the groups they belong to. Size groupings were based on the $90 \%$ confidence interval for breeder body size (see methods). $N$ is the number of paired comparisons. All tests are randomized Pearson correlations. Values in bold type indicate significant relationship $(P<0.05)$

\begin{tabular}{llll}
\hline Estimates of pairwise relatedness of & $r$ & $N$ & $P$ \\
\hline All individuals to all individuals & 0.20 & 344 & $\mathbf{0 . 0 0 0 4}$ \\
Large males to large males & 0.17 & 300 & $\mathbf{0 . 0 0 2}$ \\
Large females to large females & 0.22 & 332 & $\mathbf{0 . 0 0 0 1}$ \\
Small males to small males & 0.19 & 148 & $\mathbf{0 . 0 2}$ \\
Small females to small females & 0.10 & 203 & 0.16 \\
Large males to large females & 0.19 & 318 & $\mathbf{0 . 0 0 0 7}$ \\
Small males to small females & 0.19 & 247 & $\mathbf{0 . 0 0 2}$ \\
\hline
\end{tabular}

between physical distance and relatedness to same-class individuals held for large males, large females and small males, but not for small females (Table 5). We also compared relatedness between opposite-sexed individuals (within a size class) and found that, for both large and small fish, the mean relatedness between males and females increased with the distance between their groups (Table 5).

Within a subpopulation, there was no evidence of sexbiased dispersal. Mean relatedness between large males from different groups was not different than that between large females from different groups $\left(N_{\mathrm{M}}=300, N_{\mathrm{F}}=332\right.$, $P=0.15$; Fig. 2a). Similarly, the relatedness of small males and small females to other same-class individuals from different groups was equivalent $\left(N_{\mathrm{M}}=148, N_{\mathrm{F}}=203, P=0.25\right.$; Fig. 2a).

\section{Dispersal between subpopulations}

Large males were more related to large males in other subpopulations than were large females were to other large females $\left(N_{\mathrm{M}}=1000, N_{\mathrm{F}}=1000, P<0.001\right.$; Fig. $\left.2 \mathrm{~b}\right)$, 

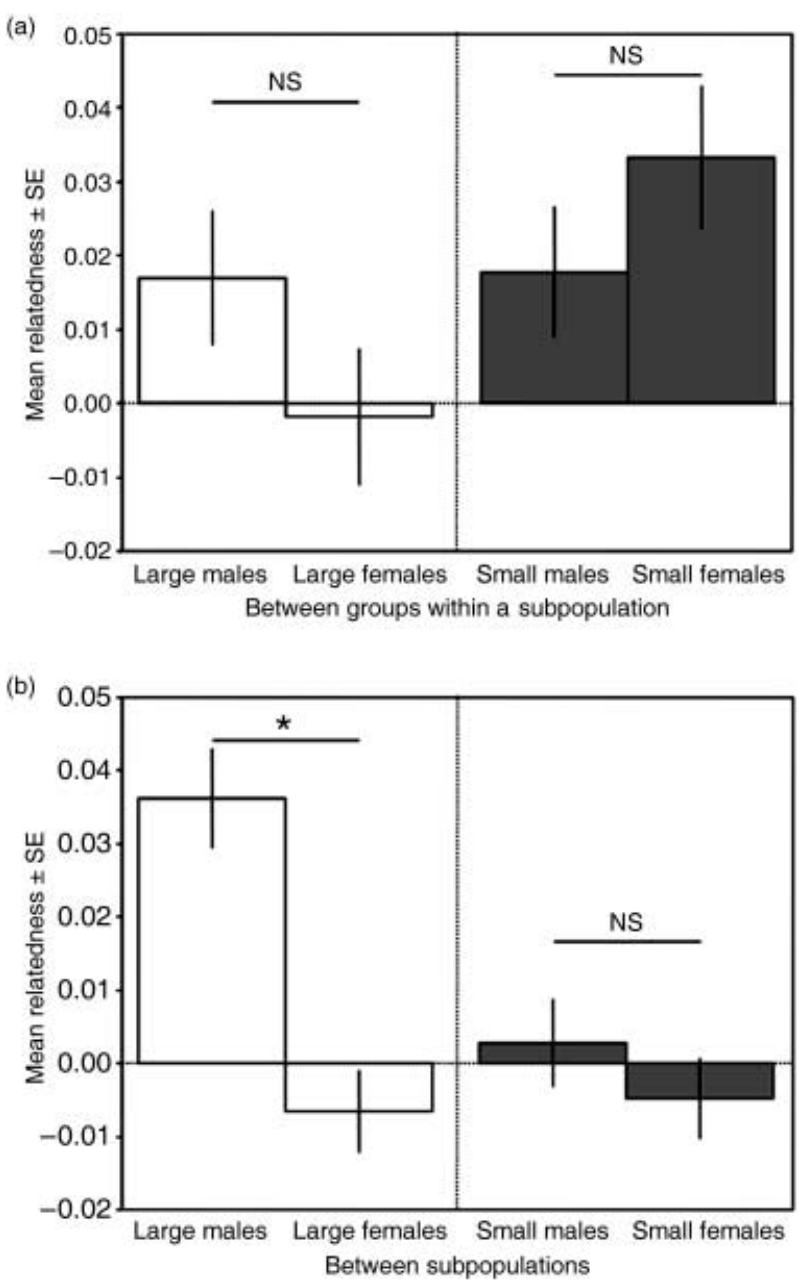

Fig. 2 Mean pairwise relatedness (Queller's $r$, mean \pm SE) between individuals of the same size and sex class (large individuals are in white and small in grey): (a) In different groups within a subpopulation; (b) In different subpopulations.

suggesting that large males may disperse farther or more often than large females. Further, large males were actually more related to large males from other subpopulations than they were to large males from their own subpopulation (that is, their mean relatedness to large males from both their group and other groups within their subpopulation; $\left.N_{\text {same }}=991, N_{\text {diff }}=1000, P=0.01\right)$, while large females were more related to large females from their own subpopulation $\left(N_{\text {same }}=1000, N_{\text {diff }}=1000, P=0.04\right)$. No such patterns were observed among small fish: there was no difference in the mean relatedness between males and females $\left(N_{\mathrm{M}}=1000, N_{\mathrm{F}}=1000, P=0.36\right.$; Fig. 2b).

\section{Discussion}

We confirmed that intrasexual competition for breeding positions was higher for males than females; large males were more related across subpopulations than were females and this sex difference was not found among small individuals in the population. These results are consistent with the idea that costs of dispersal between subpopulations are high, and it may typically only pay large males to do so. Large males may be better able to resist the costs of dispersal and may gain considerable fitness benefits from holding a breeding position in multiple territories. However, we cannot rule out an alternative explanation for the male-bias dispersal results; females may benefit from philopatry (local resource enhancement) more than males. For example, females may benefit more than males from a long familiarity with their breeding territory (Greenwood 1980). This possibility bears further attention in future studies. Regardless of the source of dispersal pressure, between-subpopulation movement is primarily restricted to large males.

Relatedness between subpopulations declines with distance between them (Stiver et al. 2004). Previous work had suggested a similar genetic structure on a narrow scale (isolation by distance between groups within a subpopulation; Balshine et al. 2001; Heg et al. 2004; Bergmüller et al. 2005); however, we found no evidence that relatedness between individuals in groups declines with increased distance between their groups. In fact, within a subpopulation, all individuals (with the exception of small females) appeared to settle farther away from their same class relatives than from nonrelatives. This result suggests that individuals move away from their same-sex relatives, perhaps to decrease the chance of kin competition. Within a size class, relatedness between males and females also increased with the distance between the groups they were residing in, suggesting that individuals may move away from their opposite-sex relatives as a mechanism of inbreeding avoidance. It may be that both forces are influencing individual dispersal. However, when we examined relatedness among breeding pairs in the field, no evidence of inbreeding avoidance was detected in this Neolamprologus pulcher population (Stiver et al. submitted). It is possible that the apparent movement of individuals away from their opposite sex relatives is a by-product of their movement away from same-sex kin. Finally, the findings involving small individuals must be interpreted with caution, as patterns of relatedness among small individuals with regard to distance may not be independent of those of their putative parents (the large individuals).

The difference in dispersal biases between and within subpopulations may be due to differential risk associated with small- vs. large-scale movement. Risk of dispersal is expected to increase with distance and the degree of inexperience or lack of knowledge of the terrain/habitat (Bergmüller et al. 2005). N. pulcher have been shown to move to visit neighbouring groups and even are able to shelter temporarily in another group's brood chamber or 
secondary shelter (Bergmüller et al. 2005); thus, fish have the opportunity to gain information about the location of shelter and other features of the terrain outside their own territories that can be accessed during within-subpopulation dispersal. However, individuals lack landscape and shelter information in and around unexplored neighbouring subpopulations. The maximum recorded dispersal distance by an individual N. pulcher is $12 \mathrm{~m}$ (Stiver et al. 2004), which is a comparable distance to the average distance between two groups in a subpopulation (14.2 $\mathrm{m}$, Table 2$)$, but far smaller than the mean distance between pairs of subpopulations (57.9 m, Table 2). Future work will further address these cost differences in dispersal across the various spatial scales.

The vast majority of cooperative breeders have delayed dispersal, and sex biases of dispersal are generally in line with those typical of their taxonomic classification: mammals typically display male-biased dispersal and birds display female-biased dispersal. For example, in Belding's ground squirrel, Spermophilus beldingi, dispersal is malebiased and these males disperse at a younger age than the occasional female disperser (Holecamp 1984). In Arabian babblers, Turdoides squamiceps, dispersal is delayed and biased towards adult females (Zahavi 1974). However, there is some variation in dispersal patterns between species. For example, dispersal by males is more common in the Seychelles warbler, Acrocephalus sechellensis (although dispersal is still biased towards older individuals; Komdeur 1998; Komdeur \& Edelaar 2001). The life history of N. pulcher is similar to that of the typical mammal: females are the primary providers of care and males experience increased mating competition relative to females (Greenwood 1980; Limberger 1983; Pusey 1987; Balshine et al. 2001; Stiver et al. 2005). Accordingly, dispersal in N. pulcher mirrors the standard mammalian pattern of dispersal. Additionally, N. pulcher displays the delayed dispersal typical of most cooperative breeders.

While the observed patterns of relatedness may indeed result from dispersal bias toward large males, this is not the only process that could lead to these findings. For example, individuals of all classes may actually leave their natal territory at equal rates, but only large males survive dispersal to a different subpopulation. Using patterns to infer process should be done with caution and on the basis of evidence from several different methods of study. In support of our suggestion of male-biased dispersal, a resampling study found that individuals travelling the farthest distance were large males, although sample sizes were small (Stiver et al. 2004). Also, experimental creation of breeding positions revealed that male breeding vacancies are most frequently filled by a new male joining the group, while female vacancies tend to be filled by inheriting group members (Stiver et al. 2006). Future work should focus on the long-term monitoring of groups to determine conclusively whether dispersal is primarily the domain of large males. Technological advances may soon allow for long-term electronic, deep $(11 \mathrm{~m})$ underwater monitoring of even such small (1-6g) fish as N. pulcher.

In conclusion, although $N$. pulcher dispersal decreases with distance between subpopulations (Stiver et al. 2004), within a subpopulation, individuals generally appear to be moving without constraints of distance and preferentially moving away from their kin, possibly to avoid competition for breeding positions (or other resources within the territory, such as shelter access). Additionally, large males appear to be the most common between-subpopulation dispersers. These findings suggest that the constraints on dispersal between subpopulations are high relative to the constraints within a subpopulation. Both distance and knowledge of availability of shelter/terrain while dispersing may influence this cost differential and future work will address the relative importance of these specific factors.

\section{Acknowledgements}

We thank D. Sinyinza and R. Shapola for their assistance in capturing fish in the field, B. Chile and G. Sichinga for logistic support at the field site and Dr R. and S. Nefdt for their kind hospitality while in Lusaka. A. Dang and L. DeSousa are thanked for their invaluable advice and assistance with the genotyping, and Dr M. Taylor and Dr L. Ruber for their help during the optimization stage. S. Marsh-Rollo greatly assisted with field logistics and with comments on both the analyses and the manuscript. Thanks also go to Dr E. Bressler, Dr B. G. Galef, Dr F. Rousset and three anonymous reviewers for their helpful comments on the manuscript. The research was funded by a Natural Sciences and Engineering Research Council of Canada Discovery Grant and Canadian Foundation for Innovation and Ontario Innovation Trust awards to S.B., and an Ontario Graduate Scholarship to K.S. This research was conducted with the permission and cooperation of Dr H. Phiri, Dr Ngalada and Dr C. Kapasa of the Zambian Ministry of Agriculture, Food and Fisheries.

\section{References}

Balshine S, Leach B, Neat F, Reid H, Taborsky M, Werner N (2001) Correlates of group size in a cooperatively breeding cichlid fish (Neolamprologus pulcher). Behavioral Ecology and Sociobiology, 50, 134-140.

Balshine-Earn S, Neat FC, Reid H, Taborsky M (1998) Paying to stay or paying to breed? Field evidence for direct benefits of helping behaviour in a cooperatively breeding fish. Behavioral Ecology, 9, 432-438.

Bengtsson BO (1978) Avoiding inbreeding: at what cost? Journal of Theoretical Biology, 73, 439-444.

Bergmüller R, Heg D, Peer K, Taborsky M (2005) Extended safe havens and between-group dispersal of helpers in a cooperatively breeding cichlid. Behaviour, 142, 1643-1667.

Brandtmann G, Scandura M, Trillmich F (1999) Female-female conflict in the harem of a snail cichlid (Lamprologus ocellatus): behavioural interactions and fitness consequences. Behaviour, 136, 1123-1144.

Burland TM, Barratt EM, Nichols RA, Racey PA (2001) Mating patterns, relatedness and the basis of natal philopatry in the brown long-eared bat, Plecotus auritus. Molecular Ecology, 10, 1309-1321. 
Clarke AB (1978) Sex ratio and local resource competition in a prosimian primate. Science (Washington D.C.), 201, 163-165.

Cockburn A (1992) Habitat heterogeneity and dispersal: environmental and genetic patchiness. In: Animal Dispersal (eds Stenseth NC, Lidiker WZ), pp. 65-95. Chapman \& Hall, London.

Cooper CB, Walters JR (2002) Experimental evidence of disrupted dispersal causing decline of an Australian passerine in fragmented habitat. Conservation Biology, 16, 471-478.

Desjardins JK, Fitzpatrick JL, Stiver KA, Milligan N, Van Der Kraak GJ, Balshine S (In press) Costs and benefits of polygyny in the cichlid, Neolamprologus pulcher. Animal Behaviour.

Dierkes P, Heg D, Taborsky M, Skubic E, Achmann R (2005) Genetic relatedness in groups is sex-specific and declines with age of helpers in a cooperatively breeding cichlid. Ecology Letters, 8, 968-975.

Ekman J, Baglione V, Eggers S, Griesser M (2001) Delayed dispersal: living under the reign of nepotistic parents. Auk, 118, 1-10.

Ekman J, Dickinson JL, Hatchwell BJ, Griesser M (2004) Delayed dispersal. In: Ecology and Evolution of Cooperative Breeding in Birds (eds Koenig ED, Dickinson JL), pp. 35-47. Cambridge University Press, Cambridge, UK.

Emlen ST (1982) The evolution of helping. I. An ecological constraints model. The American Naturalist, 119, 29-39.

Emlen ST (1994) Benefits, constraints and the evolution of family. Trends in Ecology \& Evolution, 9, 282-284.

Fitzpatrick JL, Desjardins JK, Stiver KA, Montgomerie R, Balshine S (2006) Male reproductive suppression in the cooperatively breeding fish Neolamprologus pulcher. Behavioral Ecology, 17, 25-33. doi: 10.1093/beheco/ari090.

Goodnight KF, Queller DC (1999) Computer software for performing likelihood tests of pedigree relationship using genetic markers. Molecular Ecology, 8, 1231-1234.

Goudet J, Perrin N, Waser P (2002) Tests for sex-biased dispersal using bi-parentally inherited genetic markers. Molecular Ecology, 11, 1103-1114.

Greenwood PJ (1980) Mating systems, philopatry and dispersal in birds and mammals. Animal Behaviour, 26, 645-652.

Greenwood PJ, Harvey PH (1982) The natal and breeding dispersal of birds. Annual Review of Ecology and Systematics, 13, 1-21.

Hamilton WD (1967) Extraordinary sex ratios. Science (Washington D.C.), 156, 477-488.

Hatchwell BJ, Komdeur J (2000) Ecological constraints, life history traits and the evolution of cooperative breeding. Animal Behaviour, 59, 1079-1086.

Heg D, Bachar Z, Brouwer L, Taborsky M (2004) Predation risk is an ecological constraint for helper dispersal in a cooperatively breeding cichlid. Proceedings of the Royal Society of London. Series B, Biological Sciences, 271, 2367-2374.

Holecamp KE (1984) Natal dispersal in Belding's ground squirrels (Spermophilus beldingi). Behavioral Ecology and Sociobiology, 16, 21-30.

Jadwiszczack P (2002) RUNDOM Projects 1.1. Available at http:// pjadw.tripod.com/rsite.htm.

Johst KJ, Brandl R (1999) Natal versus breeding dispersal: evolution in a model system. Evolution Ecological Research, 1, 911-921.

Knight ME, van Oppen MJH, Smith HL, Rico C, Hewitt M, Turner GF (1999) Evidence for male-biased dispersal in Lake Malawi cichlids from microsatellites. Molecular Ecology, 8, 1521-1527.

Koenig WD, Pitelka FA (1981) Ecological factors in the evolution of cooperative breeding in birds. In: Natural Selection Social Behaviour: Recent Research and New Theory (eds Alexander RD, Tinkle DW), pp. 261-280. Chiron Press, New York.
Kohler U (1997) Zur Struktur und Evolution des Sozialsystems von Neolamprologus multifasciatus (Cichlidae, Pisces) des kleinsten Schneckenbuntbarsches des Tanganjika-Sees. PhD Thesis, LudwigMaximilians-Universität, München.

Komdeur J (1992) Importance of habitat saturation and territory quality for the evolution of cooperative breeding in the Seychelles warbler. Nature, 358, 493-495.

Komdeur J (1998) Long-term fitness benefits of egg sex modification by the Seychelles warbler. Ecology Letters, 1, 56-62.

Komdeur J, Edelaar P (2001) Evidence that helping at the nest does not result in territory inheritance in the Seychelles warbler. Proceedings of the Royal Society of London. Series B, Biological Sciences, 268, 2007-2012.

Konings A (1998) Tanganyika Cichlids in Their Natural Habitat. Cichlid Press, St Leon-Rot, Germany.

Leturque H, Rousset F (2004) Intersexual competition as an explanation for sex-ratio and dispersal biases in polygynous species. Evolution, 58, 2398-2408.

Limberger D (1983) Pairs and harems in a cichlid fish, Lamprologus brichardi. Zeitschrift für Tierpsychology, 62, 115-144.

Marshall TC, Slate J, Kruuk LEB, Pemberton JM (1998) Statistical confidence for likelihood-based paternity inference in natural populations. Molecular Ecology, 7, 639-655.

Morley JI, Balshine S (2003) Reproductive biology of Eretmodus cyanostictus, a cichlid fish from Lake Tanganyika. Environmental Biology of Fishes, 66, 169-179.

Motro U (1991) Avoiding inbreeding and sibling competition: the evolution of sexual dimorphism for dispersal. The American Naturalist, 137, 108-115.

Neff BD, Fu P, Gross MR (2000) Microsatellite multiplexing in fish. Transactions of the American Fish Society, 129, 584-593.

Nilsson PA, Brönmark C (2000) Prey vulnerability to a gape-size limited predator: behavioural and morphological impacts on northern pike piscivory. Oikos, 88, 539-546.

Paine RT (1976) Size-limited predation: an observational and experimental approach with the Mytilus-Pisaster interaction. Ecology, 57, 858-873.

Parker GA (1979) Sexual selection and sexual conflict. In: Sexual Selection and Reproductive Competition in Insects (eds Blum MS, Blum NA), pp. 123-166. Academic Press, New York.

Parker GA (1983) Mate quality and mating decisions. In: Mate Choice (ed. Bateson P), pp. 141-164. Cambridge University Press, Cambridge, UK.

Parker A, Kornfield I (1996) Polygynandry in Pseudotropheus zebra, a cichlid fish from Lake Malawi. Environmental Biology Fishes, 47, 345-352.

Perrin N, Mazalov V (2000) Local competition, inbreeding, and the evolution of sex-biased dispersal. The American Naturalist, 155, 116-127.

Pruett-Jones SG, Lewis MJ (1990) Sex ratio and habitat limitation promote delayed dispersal in superb fairy-wrens. Nature, 348, 541-542.

Prugnolle F, de Meeus T (2002) Inferring sex-biased dispersal from population genetic tools: a review. Heredity, 88, 161-165.

Pusey AE (1987) Sex-biased dispersal and inbreeding avoidance in birds and mammals. Trends in Ecology \& Evolution, 2, 295-299.

Queller DC, Goodnight KF (1989) Estimating relatedness using genetic markers. Evolution, 43, 258-275.

Richardson DS, Burke T, Komdeur J (2002) Direct benefits and the evolution of female-biased cooperative breeding in Seychelles warblers. Evolution, 56, 2313-2321. 
Rousset F (2002) Inbreeding and relatedness coefficients: what do they measure? Heredity, 88, 371-380.

Russell EM, Rowley I (1993) Philopatry or dispersal: competition for territory vacancies in the splendid fairy-wren, Malurus splendens. Animal Behavior, 45, 519-539.

Schliewen UK, Rassmann K, Markmann M, Markert J, Kocher TD, Tautz D (2001) Genetic and ecological divergence of a monophyletic cichlid species pair under fully sympatric conditions in Lake Ejagham, Cameroon. Molecular Ecology, 10, 1471-1488.

Schuelke M (2000) An economic method for the fluorescent labeling of PCR fragments. Nature Biotechnology, 18, 233-234.

Schulte-Hostedde AI, Gibbs HL, Millar JS (2001) Microgeographic genetic structure in the yellow-pine chipmunk (Tamias amoenus). Molecular Ecology, 10, 1625-1631.

Stiver KA, Dierkes P, Taborsky M, Balshine S (2004) Dispersal patterns and status change in a cooperatively breeding fish; evidence from microsatellite analyses and behavioural observations. Journal of Fish Biology, 65, 91-105.

Stiver KA, Dierkes P, Taborsky M, Gibbs HL, Balshine S (2005) Relatedness and helping in fish: examining the theoretical predictions. Proceedings of the Roy Society of London B, 272, 15931599.

Stiver KA, Fitzpatrick J, Desjardins JK, Balshine S (2006) Sex differences in rates of territory joining and inheritance in a cooperatively breeding cichlid fish. Animal Behaviour, 71, 449456.

Stiver KA, Fitzpatrick J, Desjardins JK, Neff BD, Quinn JS, Balshine $S$ (Submitted) The role of genetic relatedness among social mates. Behavioral Ecology.

Taborsky M (1984) Brood care helpers in the cichlid fish Lamprologus brichardi: their costs and benefits. Animal Behaviour, 32, 12361252.

Taborsky M, Limberger D (1981) Helpers in fish. Behavioral Ecological Sociobiology, 8, 143-145.

Taylor MI, Meardon F, Turner G, Seehausen O, Mrosso HDJ, Rico C (2002) Characterization of tetranucleotide microsatellite loci in a Lake Victorian, haplochromine cichlid fish: a Pundamilia pundamilia $\times$ Pendamilia nyererei hybrid. Molecular Ecological Notes, 2, 443-445.

Wang J (2002) An estimator for pairwise related using molecular markers. Genetics, 160, 1203-1215.

Waser PM, Austad SN, Keane B (1986) When should animals tolerate inbreeding? The American Naturalist, 128, 529-537.

Werner NY, Balshine S, Leach B, Lotem A (2003) Helping opportunities and space segregation among helpers in cooperatively breeding cichlids. Behavioral Ecology, 14, 749-756.

Whittingham LA, Dunn PO, Stapleton MK (2006) Repeatability of extra-pair mating in tree swallows. Molecular Ecology, 15, 841-849.

Zahavi A (1974) Communal nesting by the Arabian babbler: a case of individual selection. Ibis, 116, 84-87.

Zardoya R, Vollmer D, Craddock C, Streelman J, Karl S, Meyer A (1996) Evolutionary conservation of microsatellite flanking regions and their use in resolving the phylogeny of cichlid fishes (Pisces: Perciformes). Proceedings of the Royal Society of London. Series B, Biological Sciences, 263, 1589-1598.

This paper represents part of Kelly Stiver's dissertation on the evolution of dispersal biases and cooperation, research she will continue as a postdoctoral fellow at Yale University. Julie Desjardins, a postdoctoral fellow at Stanford University, is interested in the mechanisms underlying parental care and dominance. A Ph.D. candidate at McMaster University, John Fitzpatrick examines mating systems and sperm competition. Bryan Neff, an Assistant Professor of Biology, is a molecular and behavioural ecologist examining mating and parental care. James S. Quinn is a Professor of Biology interested in the study of colonial and communal nesting species, with a focus on avian plural-breeding jointnesting systems. Sigal Balshine is a behavioural ecologist and Associate Professor of Psychology, Neuroscience and Behaviour. Her research interests focus on evolution of parental care and cooperation in fishes and other vertebrates. 
2984 K. A. STIVER ET AL.

\section{Appendix}

Summary of restricted sample analyses. Pairs of individuals or groups were randomly selected to ensure that each group/individual contributed to only a single data point.

A. Within-subpopulation correlation analyses comparing the average relatedness between specific types of individuals to the distance between the groups they belong to. Size groupings were based on the $90 \%$ confidence interval for breeding-size (see methods). $N$ is the number of paired comparisons. Values in bold represent $P>0.05$. All tests are randomized Pearson correlations

\begin{tabular}{llll}
\hline Estimates of pairwise relatedness of & $r$ & $N$ & $P$ \\
\hline All individuals to all individuals & 0.63 & 29 & $\mathbf{0 . 0 0 0 4}$ \\
Large males to large males & 0.55 & 24 & $\mathbf{0 . 0 0 6}$ \\
Large females to large females & 0.50 & 25 & $\mathbf{0 . 0 1}$ \\
Small males to small males & 0.54 & 19 & $\mathbf{0 . 0 2}$ \\
Small females to small females & 0.06 & 23 & 0.77 \\
Large males to large females & 0.61 & 27 & $\mathbf{0 . 0 0 0 8}$ \\
Small males to small females & 0.47 & 25 & $\mathbf{0 . 0 2}$
\end{tabular}

B. Mean relatedness of same size/sex class individuals. Type of comparison and sample sizes (number of paired comparisons) are indicated. Values in bold represent $P>0.05$. All tests are two-sample randomization/permutation tests

\begin{tabular}{|c|c|c|c|c|}
\hline Comparison group 1 & Comparison group 2 & $N_{1}$ & $\mathrm{~N}_{2}$ & $P$ \\
\hline \multicolumn{5}{|c|}{ Relatedness to individuals in different groups } \\
\hline Large males & Large females & 24 & 25 & 0.95 \\
\hline Small males & Small females & 19 & 23 & 0.57 \\
\hline \multicolumn{5}{|c|}{ Relatedness to individuals in different subpopulations } \\
\hline Large males & Large females & 64 & 56 & 0.03 \\
\hline Small males & Small females & 54 & 71 & 0.19 \\
\hline \multicolumn{5}{|c|}{ Relatedness to individuals in same vs. different subpopulations } \\
\hline Large males to same & Large males to different & 67 & 64 & 0.0002 \\
\hline Large females to same & Large females to different & 63 & 56 & 0.003 \\
\hline
\end{tabular}

